\title{
Characteristics of elderly patients with COPD and newly diagnosed lung cancer, and factors associated with treatment decision
}

This article was published in the following Dove Press journal:

International Journal of COPD

4 July 2016

Number of times this article has been viewed

\section{Jianwen Qin \\ Guangsheng Li \\ Jingmin Zhou}

Department of Respiratory and Critical Care Medicine, Tianjin

Chest Hospital, Tianjin, People's Republic of China
Correspondence: Jianwen Qin

Department of Respiratory and Critical Care Medicine, Tianjin Chest Hospital, 26I Tianjin Taierzhuang South Road, Jinnan, Tianjin 300222, People's Republic of China

Tel +86 I56 92296166

Fax +86 22 88185338

Email qinjianwen2005@aliyun.com
Objective: To investigate the clinical features, diagnosis, and treatment status of elderly patients with chronic obstructive pulmonary disease (COPD) complicated with lung cancer.

Patients and methods: This was a retrospective study of 206 patients aged $>60$ years with COPD and newly diagnosed lung cancer at the Tianjin Chest Hospital Respiratory Centre between September 2008 and September 2013. Lung function, radiology, and clinical data were retrieved. Results: Among all patients, 57\% (117/206) were hospitalized due to acute COPD aggravation, 47\% (96/206) had COPD grade III or IV, 95\% (195/206), showed diffusion dysfunction in pulmonary function examination, $90 \%$ (185/206) had a history of smoking, and 26\% (54/206) were treated with inhaled corticosteroids for COPD treatment. Ninety-eight patients suffered from squamous carcinoma, 73 from adenocarcinoma, and 35 from small-cell carcinoma. Clinical staging was I in 36 patients, II in 47 patients, III in 78 patients, and IV in 45 patients. Initial treatments were surgery in 59 patients, chemotherapy in 30 patients, and no treatment in 117 patients. Multivariate analysis showed that age $(P<0.001)$, COPD grades $(P=0.01)$, clinical staging $(P<0.001)$, and pulmonary diffusion function $(P=0.007)$ were independent factors associated with patients with COPD being given treatments for lung cancer.

Conclusion: Younger patients with lower COPD grades, earlier lung cancer stage, and better pulmonary diffusion function are more likely to receive treatments.

Keywords: chronic obstructive pulmonary disease, lung cancer, treatment, diagnosis

\section{Introduction}

Chronic obstructive pulmonary disease (COPD) is a pulmonary disease characterized by persistent airflow limitation associated with a chronic inflammatory response in airways, lungs, and the whole body, resulting in the destruction of lung tissue and the long-term decline in lung function. ${ }^{1,2}$ It mainly affects men, smokers, and people aged $>40$ years ${ }^{1,2}$ and is the fourth cause of mortality worldwide, ${ }^{1,2}$ showing a prevalence of $4 \%-10 \%{ }^{3,4}$ The symptoms may be variable in severity and may hide other pulmonary diseases such as lung cancer. ${ }^{1,2}$

Lung cancer accounts for $\sim 12 \%$ of all cancer patients. ${ }^{5}$ The risk factors for lung cancer include smoking, occupational exposure, and a family history of lung cancer. ${ }^{6}$ The patients with COPD are at increased risk of lung cancer because of the chronic systemic and local inflammatory state and lung tissue remodeling. ${ }^{7,8}$ A 5-year study in the US revealed that the incidence of lung cancer in patients with COPD was as high as $16.7 / 1,000$ cases per year. ${ }^{9}$

The symptoms of COPD may lead to difficulties for the early diagnosis of lung cancer. In addition, the declined pulmonary function may cause loss of treatment 
opportunity in many patients with COPD and lung cancer, especially in elderly patients who also frequently suffer from comorbidities. The severity of COPD may limit the surgical options because of the low lung function. ${ }^{10}$ The patients with COPD might benefit more from minimally invasive surgical approaches or nonsurgical treatments. ${ }^{11}$ Nevertheless, despite the best treatment approach, the overall prognosis of patients with COPD and lung cancer is worse than that of patients with lung cancer but without COPD. ${ }^{12}$

The present study was a retrospective series of 206 elderly patients hospitalized due to COPD and lung cancer between September 2008 and September 2013. The aim was to investigate the clinical features, diagnosis, and treatment status of elderly patients with COPD complicated with lung cancer.

\section{Patients and methods Study design}

This was a retrospective case series of patients hospitalized with COPD and newly diagnosed lung cancer at the Tianjin Chest Hospital Respiratory Centre between September 2008 and September 2013. The study was approved by the ethics committee of the Tianjin Chest Hospital Respiratory Centre. The need for individual consent was waived by the committee because of the retrospective nature of the study.

\section{Patients}

A total of 206 patients were included. The diagnosis and classification of COPD was made according to the Global Initiative for Chronic Obstructive Lung Disease statement. ${ }^{2}$ Patients with any other chronic pulmonary diseases such as bronchiectasis, tuberculosis, bronchial asthma, or diffuse panbronchiolitis were excluded. The diagnosis of lung cancer abided by the classification of the 2004 World Health Organization classification of lung tumors. ${ }^{13}$ The cancer was pathologically diagnosed by bronchoscopic biopsy, superficial lymph node biopsy, computer tomography (CT)-guided percutaneous lung biopsy, and/or pleural effusion examinations.

\section{Data collection}

Clinical, pathological, lung function, and radiological data were collected through reviewing medical records and imaging data. Lung function was expressed using forced vital capacity (FVC), percentage of forced expiratory volume in 1 second $\left(\mathrm{FEV}_{1}\right)$ to predicted value $\left(\% \mathrm{FEV}_{1}\right)$, percentage of $\mathrm{FEV}_{1}$ to $\mathrm{FVC}\left(\mathrm{FEV}_{1} / \mathrm{FVC}\right)$, and percentage of diffusion capacity for carbon monoxide of lung to its predicted value $(\% \mathrm{DLCO})$ after the bronchodilation test. The signs of emphysema in the chest CT were identified by experienced radiologists. The pathological examination of the lung cancer was reviewed by experienced pathologists.

\section{Statistical analysis}

Data collection and statistical analyses were carried out using SPSS 22.0 (IBM Corporation, Armonk, NY, USA). Continuous variables were presented as mean \pm standard deviation and were analyzed using analysis of variance with the Tukey's post hoc test. Categorical variables were presented as frequencies and were analyzed using the Fisher's exact test. Correlations were analyzed using the Spearman's rank test. All variables associated with thoracic surgery were introduced into a multiple logistic regression model (forward stepwise). Multivariate odds ratios (ORs) and 95\% confidence intervals (CIs) were presented. A two-sided $P$-value of $<0.05$ was considered statistically significant.

\section{Results}

\section{Characteristics of the patients}

Table 1 presents the characteristics of the patients. Among the 206 patients with COPD and newly diagnosed lung cancer, there were 128 men and 78 women, with a mean age of $69.7 \pm 5.1$ years. Among these patients, $90 \%(185 / 206)$ had a history of smoking; 57\% (117/206) were admitted due to acutely aggravated COPD, 33\% (68/206) had severe symptoms (hemoptysis, chest pain, hoarseness, etc), and $10 \%(21 / 206)$ had pulmonary shadows observed during radiological examination. All patients had symptoms such as cough, sputum, and wheezing after activities. The pulmonary function examination indicated that 195 (95\%) patients suffered from declined pulmonary diffusion function. Fifty-four (26\%) patients used inhaled corticosteroids for COPD treatment.

There were 98 cases (48\%) of squamous carcinoma, 73 cases $(35 \%)$ of adenocarcinoma, and 35 cases $(17 \%)$ of small-cell lung cancer. In terms of clinical staging, 36 patients had stage I, 47 had stage II, 78 had stage III, and 45 had stage IV.

All 206 patients underwent chest X-ray and CT examination. Emphysema signs were found in all patients. In addition, $132,10,36$, and 28 patients showed tumor mass, pneumonia, atelectasis, and pleural effusion, respectively.

The patients were divided according to COPD severity: $41,69,68$, and 28 patients were of COPD grades I, II, III, 
Table I Characteristics of the patients according to the severity of COPD

\begin{tabular}{|c|c|c|c|c|c|c|c|}
\hline Characteristics & $\begin{array}{l}\text { All } \\
(\mathrm{N}=206)\end{array}$ & $\begin{array}{l}\text { COPD I } \\
(n=4 I)\end{array}$ & $\begin{array}{l}\text { COPD II } \\
(n=69)\end{array}$ & $\begin{array}{l}\text { COPD III } \\
(n=68)\end{array}$ & $\begin{array}{l}\text { COPD IV } \\
(n=28)\end{array}$ & $P$-value & $P$ for trend \\
\hline Age, years, mean $\pm S D$ & $69.7 \pm 5.1$ & $69.6 \pm 5.3$ & $69.1 \pm 4.7$ & $70.3 \pm 5.1$ & $70.1 \pm 5.4$ & 0.78 & 0.32 \\
\hline Sex, n (\%) & & & & & & 0.22 & 0.70 \\
\hline Male & $128(62.1)$ & $25(61.0)$ & $48(69.6)$ & $46(67.6)$ & $19(67.9)$ & & \\
\hline Female & $78(37.9)$ & $16(39.0)$ & $21(30.4)$ & $22(32.4)$ & $9(32.1)$ & & \\
\hline Smoking history, mean \pm SD, pack/year & $35 \pm 23$ & $4 I \pm 24$ & $33 \pm 23$ & $34 \pm 21$ & $32 \pm 27$ & 0.68 & 0.16 \\
\hline Lung cancer, $\mathrm{n}(\%)$ & & & & & & 0.57 & 0.66 \\
\hline Stage I & $36(17.5)$ & $6(14.6)$ & $12(17.4)$ & $14(20.6)$ & $4(14.3)$ & & \\
\hline Stage II & $47(22.8)$ & $10(24.4)$ & $18(26.1)$ & $13(19.1)$ & $6(21.4)$ & & \\
\hline Stage IIla & $38(18.4)$ & $8(19.5)$ & II (I5.9) & $12(17.6)$ & $7(25.0)$ & & \\
\hline Stage IIlb & $40(19.4)$ & $10(24.4)$ & $17(24.6)$ & $8(I 1.8)$ & $5(17.9)$ & & \\
\hline Stage IV & $45(21.8)$ & $7(17.1)$ & II (I5.9) & $21(30.9)$ & $6(21.4)$ & & \\
\hline Pathology, n (\%) & & & & & & 0.029 & 0.001 \\
\hline Adenocarcinoma & $73(35.4)$ & $22(53.7)$ & $27(39.1)$ & $17(25.0)$ & $7(25.0)$ & & \\
\hline Squamous carcinoma & $98(47.6)$ & II (26.8) & $28(40.6)$ & $40(58.8)$ & $19(67.9)$ & & \\
\hline Small-cell carcinoma & $35(17.0)$ & $8(19.5)$ & $14(20.3)$ & $11(16.2)$ & $2(7.1)$ & & \\
\hline DLCO (\% predictive value), mean \pm SD & $58.4 \pm 13.7$ & $68.2 \pm 11.5$ & $65.3 \pm 9.1$ & $51.2 \pm 11.6$ & $43.7 \pm 8.7$ & $<0.001$ & $<0.001$ \\
\hline
\end{tabular}

Abbreviation: DLCO, diffusion capacity for carbon monoxide of lung.

and IV, respectively. There were no differences among COPD grades for age, sex, and smoking history (all $P>0.05$ ), but the frequency of squamous carcinoma increased with increasing COPD grade $(P=0.03, P$ for trend $=0.001)$, and expectedly, the pulmonary diffusion function decreased with increasing COPD grade $(P<0.001, P$ for trend $<0.001$; Table 1$)$. COPD grading and cancer staging were not significantly correlated $(r=0.020, P=0.777)$.

\section{Treatments}

Initial treatments were surgery in 59 patients, chemotherapy in 30, and no treatment in 117 (Table 2). The reasons why 117 cases did not receive operation and chemotherapy are stated as follows.

All patients with stages IIIb and IV cancer $(\mathrm{n}=78)$ and some of the patients with stage IIIa cancer $(n=10)$ had no indication for operation (total, $\mathrm{n}=88 / 117,75 \%), 23 / 117(20 \%)$

Table 2 Characteristics of the patients according to the treatments for lung cancer

\begin{tabular}{|c|c|c|c|c|c|c|}
\hline Characteristics & $\begin{array}{l}\text { All } \\
(\mathrm{N}=206)\end{array}$ & $\begin{array}{l}\text { Surgery } \\
(n=59)\end{array}$ & $\begin{array}{l}\text { Chemotherapy } \\
(\mathrm{n}=30)\end{array}$ & $\begin{array}{l}\text { No treatment } \\
(n=\mid 17)\end{array}$ & $P$-value & $P$ for trend \\
\hline Age, years, mean $\pm S D$ & $69.7 \pm 5.1$ & $67.2 \pm 4.7$ & $67.2 \pm 4.0$ & $71.7 \pm 8.1$ & $<0.001$ & $<0.001$ \\
\hline Sex, n (\%) & & & & & 0.87 & 0.52 \\
\hline Male & $128(62.1)$ & $35(59.3)$ & $19(63.3)$ & $74(63.2)$ & & \\
\hline Female & $78(37.9)$ & $24(40.7)$ & II (36.7) & $43(36.8)$ & & \\
\hline Smoking history, mean \pm SD, pack/year & $35 \pm 23$ & $36 \pm 25$ & $40 \pm 24$ & $33 \pm 23$ & 0.22 & 0.44 \\
\hline Pathology, n (\%) & & & & & 0.001 & 0.85 \\
\hline Squamous carcinoma & $98(47.6)$ & $25(42.4)$ & $14(46.7)$ & $59(50.4)$ & & \\
\hline Adenocarcinoma & $73(35.4)$ & $30(50.8)$ & $5(16.7)$ & $38(32.5)$ & & \\
\hline Small-cell carcinoma & $35(17.0)$ & $4(6.8)$ & II (36.7) & $20(17.1)$ & & \\
\hline Lung cancer, n (\%) & & & & & $<0.001$ & $<0.001$ \\
\hline Stage I & $36(17.5)$ & $20(33.9)$ & $5(16.7)$ & II (9.4) & & \\
\hline Stage II & $47(22.8)$ & $27(45.8)$ & $9(30.0)$ & II (9.4) & & \\
\hline Stage IIla & $38(18.4)$ & $12(20.3)$ & $9(30.0)$ & $17(14.5)$ & & \\
\hline Stage IIlb & $40(19.4)$ & 0 & $6(20.0)$ & $34(29.1)$ & & \\
\hline Stage IV & $45(21.8)$ & 0 & I (3.33) & $44(37.6)$ & & \\
\hline COPD, n (\%) & & & & & $<0.001$ & $<0.001$ \\
\hline Grade I & $4 \mid(19.9)$ & $24(40.7)$ & $3(10.0)$ & $14(12.0)$ & & \\
\hline Grade II & $69(33.5)$ & $28(47.5)$ & $6(20.0)$ & $35(29.9)$ & & \\
\hline Grade III & $68(33.0)$ & $7(I 1.9)$ & $16(53.3)$ & $45(38.5)$ & & \\
\hline Grade IV & $28(13.6)$ & 0 & $5(16.7)$ & $23(19.7)$ & & \\
\hline DLCO (\% predictive value), mean \pm SD & $58.4 \pm 13.6$ & $70.2 \pm 6.1$ & $57.0 \pm 7.7$ & $52.8 \pm 13.7$ & $<0.001$ & $<0.001$ \\
\hline
\end{tabular}

Abbreviation: DLCO, diffusion capacity for carbon monoxide of lung. 
Table 3 Univariate and multivariate analyses of independent factors associated with the decisions for treatment

\begin{tabular}{|c|c|c|c|c|c|c|}
\hline & \multicolumn{3}{|c|}{ Univariate } & \multicolumn{3}{|c|}{ Multivariate } \\
\hline & OR & $95 \% \mathrm{Cl}$ & $P$-value & OR & $95 \% \mathrm{Cl}$ & $P$-value \\
\hline Age (per I year) & 0.808 & $0.75 I-0.868$ & $<0.001$ & 0.798 & $0.714-0.892$ & $<0.001$ \\
\hline COPD grade & 0.498 & $0.36 \mathrm{I}-0.687$ & $<0.001$ & 0.455 & $0.248-0.836$ & 0.011 \\
\hline Clinical staging & 0.347 & $0.260-0.463$ & $<0.001$ & 0.320 & $0.220-0.468$ & $<0.001$ \\
\hline DLCO & 1.101 & $1.067-1.136$ & $<0.001$ & 1.078 & $1.021-1.139$ & 0.007 \\
\hline
\end{tabular}

Abbreviations: OR, odds ratio; $\mathrm{Cl}$, confidence interval; $\mathrm{DLCO}$, diffusion capacity for carbon monoxide of lung.

patients had poor lung function and could not endure operation, and 6/117 (5\%) patients were old or with comorbidities that made them ineligible for surgery. The prechemotherapy evaluation was based on age, performance status score, cardiopulmonary function, and with/without/severity grade of, infection. The reasons for not receiving chemotherapy were 25 (20\%) patients were older than 75 years; 60 (51\%) patients had a performance status score $\geq 2$, among which 45 had COPD III or IV; ten (9\%) patients had abnormal hepatic or renal function; eleven (10\%) patients had COPD combined with severe infection; and eleven (10\%) patients refused chemotherapy.

Compared with untreated patients, patients who received treatments were younger $(P<0.001, P$ for trend $<0.001)$, were at earlier cancer stage $(P<0.001, P$ for trend $<0.001)$, had lower COPD grade $(P<0.001, P$ for trend $<0.001)$, and had a better pulmonary diffusion function $(P<0.001, P$ for trend $<0.001)$. Worth mentioning, compared with untreated patients, the patients who received treatments showed a higher frequency of adenocarcinoma $(P=0.001)$, but this association was probably due to the types of treatment for different types of cancer.

\section{Decision making for lung cancer treatment}

Dependent variable was categorized as treated (surgery and chemotherapy) and nontreated. Univariate and multivariate analyses showed that age (per 1 year; univariate: $\mathrm{OR}=0.81$, 95\% CI: $0.75-0.87, P<0.001$; multivariate: $\mathrm{OR}=0.80$, 95\% CI: $0.71-0.89, P<0.001$ ), COPD grades (univariate: OR $=0.50,95 \%$ CI: $0.36-0.69, P<0.001$; multivariate: $\mathrm{OR}=0.46,95 \% \mathrm{CI}: 0.25-0.84, P=0.01$ ), clinical staging (univariate: $\mathrm{OR}=0.35,95 \% \mathrm{CI}: 0.26-0.46, P<0.001$; multivariate: $\mathrm{OR}=0.32,95 \% \mathrm{CI}: 0.22-0.47, P<0.001)$, and pulmonary diffusion function (univariate: $\mathrm{OR}=1.10$, 95\% CI: $1.07-1.14, P<0.001$; multivariate: $\mathrm{OR}=1.08$, 95\% CI: $1.02-1.14, P=0.007)$ were independent factors associated with patients with COPD being given treatments for lung cancer (Table 3).

\section{Discussion}

Patients with COPD and lung cancer have a poor prognosis. The aim of this study was to investigate the clinical features, diagnosis, and treatment status of elderly patients with COPD complicated with lung cancer. The results showed that among the 206 patients, $57 \%$ were hospitalized due to acute COPD aggravation, 95\% showed diffusion dysfunction in pulmonary function examination, and $90 \%$ had a history of smoking. The initial treatments were surgery in 59 patients, chemotherapy in 30 patients, and no treatment in 117 patients. Multivariate analysis showed that age, COPD grades, clinical staging, and pulmonary diffusion function were independent factors associated with patients with COPD being given treatments for lung cancer.

A number of epidemiological studies ${ }^{7,14}$ revealed that COPD is associated with an increased risk of lung cancer. Indeed, COPD increases the risk of lung cancer by four to five times, and $\sim 30 \%$ of patients with COPD die from lung cancer. In all, $50 \%-80 \%$ of patients with lung cancer also suffer from COPD. For a long time, smoking has been recognized as the most important risk factor for lung cancer. ${ }^{15}$ Patients with COPD usually have a history of heavy smoking, especially elderly patients, which may be an important contributor to the increased risk of lung cancer in patients with COPD. Nevertheless, the large amount of lung damage and remodeling observed in COPD might also play a role in the development of lung cancer, as well as the chronic inflammatory state. ${ }^{78}$ In this study, smoking patients accounted for $90 \%$ of all the patients. A previous study ${ }^{9}$ enrolled 2,507 patients with COPD but without initial clinical or radiological evidence of lung cancer and was conducted with a median follow-up of 60 months, during which anthropometric indexes, smoking history, lung cancer, diagnosis time of lung cancer, and histological types at baseline were recorded. The study results revealed that the incidence of lung cancer was lower in patients with more severe airflow obstruction; in addition, lung cancer was associated with lung function of grades I and II, age, low body mass index, and $\%$ DLCO $<80 \%$. Previous studies showed that severe 
airway obstruction is associated with lung cancer, ${ }^{16-18}$ but this is controversial. ${ }^{9}$ In the present study, $95 \%$ of the patients showed different degrees of decline in pulmonary diffusion function, which is a quantitative index for emphysema. ${ }^{19} \mathrm{~A}$ previous study suggested that emphysema was an independent risk factor of lung cancer. ${ }^{20}$ Squamous carcinoma is the main pathological type of lung cancer and has been shown to be associated with airway obstruction. ${ }^{21}$ However, it is still unclear why the proportion of lung adenocarcinoma is higher in patients with grade I COPD. The present study was not designed to assess the incidence of lung cancer in patients with COPD. Additional studies are still necessary to address this question.

COPD with lung cancer is difficult to detect because of the severe pulmonary symptoms of the patients. In the present study, $57 \%$ of the patients were initially admitted due to acute aggravation of COPD, 33\% because of severe symptoms (hemoptysis, chest pain, hoarseness, etc), and $10 \%$ because of radiological findings. Therefore, it might be very necessary to perform lung cancer screening in the COPD population. In 2011, a large-scale and 10-year study ${ }^{22}$ revealed that screening of patients with a smoking history using small-dose CT imaging was conducive to reduce the mortality of lung cancer. Standard X-ray screening may have some effect in the detection of lung cancer, but it is unlikely to reduce the number of lung cancer deaths. ${ }^{22}$ The probability of participants dying from lung cancer was lowered by $20 \%$ when they underwent CT scans compared with those who underwent conventional X-ray examination. ${ }^{22}$ A recent study revealed that body mass index, smoking, age, and CT emphysema signs were indexes that could help identifying high-risk patients for lung cancer. ${ }^{23}$

The treatment outcomes of COPD and lung cancer may be unfavorable due to delayed diagnosis. In this study, $<30 \%$ of the patients underwent surgery and $<15 \%$ of the patients underwent chemoradiotherapy. Studies revealed that the inhalation of corticosteroids could not only improve the symptoms but also decrease the incidence of lung cancer in patients with COPD. Indeed, Parimon et $\mathrm{al}^{24}$ conducted a 3.8-year follow-up study in 10,747 patients with COPD and found that the incidence of lung cancer was significantly decreased in patients with COPD inhaling corticosteroids, which could be significant for the prevention of lung cancer and worthy of further investigations.

In the present study, age, COPD grades, clinical staging, and pulmonary diffusion function were independent factors associated with patients with COPD being given treatments for lung cancer. These results are supported by a previous study that suggested that the knowledge of the severity of COPD is one of the most important factors for the therapeutic decision. ${ }^{25}$ These results suggested that older patients with more advanced COPD and lung cancer were less likely to be treated. Indeed, limited pulmonary reserve is a contraindication to resection of the tumor, ${ }^{10}$ but novel ablation techniques such as stereotactic radiation therapy and radiofrequency ablation are promising in these patients. ${ }^{11,26}$ Nevertheless, even if observation leads to poor outcomes of lung cancer, ${ }^{27}$ a patient cannot be proposed a treatment that he or she will be unable to endure. Additional studies are necessary to determine the most optimal approaches for these patients.

The present study is not without limitations. First, the sample size was relatively small and from a single center. Besides, the retrospective design prevented examination of factors that are not part of the routine management of the patients. Additional studies are still necessary to describe comprehensively these patients and to determine the best course of action.

\section{Conclusion}

Younger patients with lower COPD grades, earlier lung cancer stage, and better pulmonary diffusion function are more likely to receive treatments.

\section{Acknowledgment}

The authors acknowledge the help from Yuedong Zhang and Hong Zhang of Department of Radiology, Tianjin Chest Hospital, People's Republic of China, for expert assistance with CT findings.

\section{Disclosure}

The authors report no conflicts of interest in this work.

\section{References}

1. Qaseem A, Wilt TJ, Weinberger SE, et al; American College of Physicians, American College of Chest Physicians, American Thoracic Society, European Respiratory Society. Diagnosis and management of stable chronic obstructive pulmonary disease: a clinical practice guideline update from the American College of Physicians, American College of Chest Physicians, American Thoracic Society, and European Respiratory Society. Ann Intern Med. 2011;155(3):179-191.

2. Vestbo J, Hurd SS, Agustí AG, et al. Global strategy for the diagnosis, management, and prevention of chronic obstructive pulmonary disease: GOLD executive summary. Am J Respir Crit Care Med. 2013; 187(4):347-365.

3. Halbert RJ, Isonaka S, George D, Iqbal A. Interpreting COPD prevalence estimates: what is the true burden of disease? Chest. 2003; 123(5):1684-1692

4. Buist AS, McBurnie MA, Vollmer WM, et al; BOLD Collaborative Research Group. International variation in the prevalence of COPD (the BOLD Study): a population-based prevalence study. Lancet. 2007;370(9589):741-750. 
5. Siegel R, Ma J, Zou Z, Jemal A. Cancer statistics, 2014. CA Cancer J Clin. 2014;64(1):9-29.

6. Detterbeck FC, Mazzone PJ, Naidich DP, Bach PB. Screening for lung cancer: diagnosis and management of lung cancer, 3rd ed: American College of Chest Physicians evidence-based clinical practice guidelines. Chest. 2013;143(5 suppl):78S-92S.

7. de Torres JP, Bastarrika G, Wisnivesky JP, et al. Assessing the relationship between lung cancer risk and emphysema detected on low-dose CT of the chest. Chest. 2007;132(6):1932-1938.

8. Mayne ST, Buenconsejo J, Janerich DT. Previous lung disease and risk of lung cancer among men and women nonsmokers. Am J Epidemiol. 1999;149(1):13-20.

9. de Torres JP, Marín JM, Casanova C, et al. Lung cancer in patients with chronic obstructive pulmonary disease - incidence and predicting factors. Am J Respir Crit Care Med. 2011;184(8):913-919.

10. Raviv S, Hawkins KA, DeCamp MM Jr, Kalhan R. Lung cancer in chronic obstructive pulmonary disease: enhancing surgical options and outcomes. Am J Respir Crit Care Med. 2011;183(9):1138-1146.

11. Schroedl C, Kalhan R. Incidence, treatment options, and outcomes of lung cancer in patients with chronic obstructive pulmonary disease. Curr Opin Pulm Med. 2012;18(2):131-137.

12. Kiri VA, Soriano J, Visick G, Fabbri L. Recent trends in lung cancer and its association with COPD: an analysis using the UK GP research database. Prim Care Respir J. 2010;19(1):57-61.

13. Beasley MB, Brambilla E, Travis WD. The 2004 World Health Organization classification of lung tumors. Semin Roentgenol. 2005;40(2): 90-97.

14. Cosio MG, Saetta M, Agusti A. Immunologic aspects of chronic obstructive pulmonary disease. $N$ Engl J Med. 2009;360(23):2445-2454.

15. Zhang H, Cai B. The impact of tobacco on lung health in China. Respirology. 2003;8(1):17-21.

16. Celli B, Decramer M, Kesten S, et al; UPLIFT Study Investigators. Mortality in the 4-year trial of tiotropium (UPLIFT) in patients with chronic obstructive pulmonary disease. Am J Respir Crit Care Med. 2009;180(10):948-955.

17. Calverley PM, Anderson JA, Celli B, et al; TORCH investigators. Salmeterol and fluticasone propionate and survival in chronic obstructive pulmonary disease. $N$ Engl J Med. 2007;356(8):775-789.
18. Vestbo J, Anderson W, Coxson HO, et al; ECLIPSE investigators. Evaluation of COPD longitudinally to identify predictive surrogate end-points (ECLIPSE). Eur Respir J. 2008;31(4):869-873.

19. Tsushima K, Sone S, Fujimoto K, et al. Identification of occult parechymal disease such as emphysema or airway disease using screening computed tomography. COPD. 2010;7(2):117-125.

20. Gullón JA, Suárez I, Medina A, Rubinos G, Fernández R, González I. Role of emphysema and airway obstruction in prognosis of lung cancer. Lung Cancer. 2011;71(2):182-185.

21. Papi A, Casoni G, Caramori G, et al. COPD increases the risk of squamous histological subtype in smokers who develop non-small cell lung carcinoma. Thorax. 2004;59(8):679-681.

22. National Lung Screening Trial Research Team; Aberle DR, Adams AM, et al. Reduced lung-cancer mortality with low-dose computed tomographic screening. N Engl J Med. 2011;365(5):395-409.

23. de-Torres JP, Wilson DO, Sanchez-Salcedo P, et al. Lung cancer in patients with chronic obstructive pulmonary disease. Development and validation of the COPD lung cancer screening score. Am J Respir Crit Care Med. 2015;191(3):285-291.

24. Parimon T, Chien JW, Bryson CL, McDonell MB, Udris EM, Au DH. Inhaled corticosteroids and risk of lung cancer among patients with chronic obstructive pulmonary disease. Am J Respir Crit Care Med. 2007:175(7):712-719.

25. Hashimoto N, Matsuzaki A, Okada Y, et al. Clinical impact of prevalence and severity of COPD on the decision-making process for therapeutic management of lung cancer patients. BMC Pulm Med. 2014; $14: 14$

26. Palma D, Lagerwaard F, Rodrigues G, Haasbeek C, Senan S. Curative treatment of stage I non-small-cell lung cancer in patients with severe COPD: stereotactic radiotherapy outcomes and systematic review. Int J Radiat Oncol Biol Phys. 2012;82(3):1149-1156.

27. McGarry RC, Song G, des Rosiers P, Timmerman R. Observation-only management of early stage, medically inoperable lung cancer: poor outcome. Chest. 2002;121(4):1155-1158.
International Journal of COPD

\section{Publish your work in this journal}

The International Journal of COPD is an international, peer-reviewed journal of therapeutics and pharmacology focusing on concise rapid reporting of clinical studies and reviews in COPD. Special focus is given to the pathophysiological processes underlying the disease, intervention programs, patient focused education, and self management protocols.

\section{Dovepress}

This journal is indexed on PubMed Central, MedLine and CAS. The manuscript management system is completely online and includes a very quick and fair peer-review system, which is all easy to use. Visit http://www.dovepress.com/testimonials.php to read real quotes from published authors. 